\title{
Adverse Childhood Experiences and Smoking among Urban Youths in Oyo State, South Western Nigeria
}

\author{
Mobolaji M. Salawu*1 and Eme Owoaje ${ }^{1,2}$ \\ ${ }^{1}$ Community Medicine Department, University College Hospital, Ibadan, Nigeria; ${ }^{2}$ College of Medicine, University of Ibadan, Ibadan, \\ Nigeria
}

\section{Objective}

To assess the relationship between Adverse Childhood Experiences (ACEs) and Smoking behaviors among urban youths in Oyo State, South Western Nigeria.

\section{Introduction}

Adverse childhood experiences are childhood traumas which influence the developing child and derail healthy developmental processes. The developing child attempt to cope by adopting health risk behaviors such as smoking which has been associated with adverse health outcomes which may not be apparent until many years after exposure.1,2 Research and surveillance on adverse childhood experiences and smoking is a substantially neglected area in Sub Saharan Africa including Nigeria.

\section{Methods}

We conducted a cross sectional survey of youths in urban South Western Nigeria between August and September, 2012. Respondents were selected using a multistage sampling technique. Data was collected using an interviewer administered questionnaire adapted from the Adverse Childhood Experiences questionnaires developed by the Centers for Disease Control and Prevention, USA and the Youth Risk Behavior survey 2011.3,4 Information were obtained on exposure to 10 categories of ACEs before 18 years of age (emotional, physical, and sexual abuse; emotional and physical neglect: household dysfunctions such as-witnessing domestic violence in the home, parental separation/ divorce, household substance-abuse, household mental illness and incarcerated household member) and 3 smoking behaviors (ever smoked, early smoking initiation-before age 15 and current smoking status). Data were analysed with SPSS version 21 and associations were tested using t-test, chi square test and logistic regression. Level of statistical significance was set at $5 \%$.

\section{Results}

A total of 560 participants were interviewed. The mean age of respondents was $24.8 \pm 4.1$ years. Females constituted $51.4 \%$ of respondents. At least 1 out of 10 categories of ACEs was reported by $87.9 \%$ of respondents. The most commonly reported ACEs were psychological abuse $54.8 \%$, household substance abuse $51.1 \%$, witnessing domestic violence $38.8 \%$ and parental separation/divorce $23.2 \%$. However, only $5.9 \%$ of respondents reported sexual abuse. With the exception of sexual abuse, men were more likely than women to report each category of ACEs $p<0.05$. As regards smoking behaviors, $28.0 \%$ had ever smoked, $20 \%$ initiated smoking before age 15 years and $19.1 \%$ of the respondents were currently smoking.

Respondents with 4 or more categories of ACEs (40.6\%) reported at least one smoking behavior $\mathrm{p}<0.05$.

As compared with respondents reporting no ACEs, those reporting 4 or more categories of ACEs had substantially higher risk of engaging in smoking behaviors: significantly, ever smoked was found to be 2 times more likely as the number of adverse childhood experiences reaches 4 or more $(\mathrm{OR}=2.42 ; 95 \% \mathrm{CI}=(1.26-4.65) \mathrm{p}<0.05$. The odd of currently smoking was also found higher as the number of adverse experiences increases to 4 or more (Table 1 ).

\section{Conclusions}

There was a relatively strong graded relationship between exposure to ACEs and smoking. There is a need to recognize ACEs and its consequences as a public health problem in Nigeria and commence the practice of public health surveillance to reduce the occurrence of ACEs and its effects.

Table 1: Prevalence and adjusted odds of smoking behaviours by categories/ number of adverse childhood exposures.

\begin{tabular}{|c|c|c|c|c|}
\hline Categories of ACEs & & Ever smoked & Early smoking initiation & Currently smoking \\
\hline \multirow{2}{*}{ None } & Prevalence \% & 9.6 & 9.3 \\
& OR(95\% CI)a & 1 (referent) & $\begin{array}{c}9.8 \\
\text { (referent) }\end{array}$ & \begin{tabular}{c} 
(referent) \\
\hline \multirow{2}{*}{1}
\end{tabular} \\
& Prevalence \% & 10.2 & 9.8 & 11.2 \\
& OR(95\% CI) a & $0.71(0.32-1.55)$ & $0.80(0.17-3.80)$ & $0.83(0.34-2.05)$ \\
\hline \multirow{2}{*}{2} & Prevalence \% & 14.6 & 17.0 & 15.9 \\
& OR(95\% CI) a & $0.91(0.43-1.90)$ & $1.73(0.36-8.32)$ & $1.04(0.46-2.42)$ \\
\hline \multirow{2}{*}{3} & Prevalence \% & 24.2 & 21.4 & 26.2 \\
& OR(95\% CI) a & $1.56(0.78-3.11)$ & $0.62(0.17-2.34)$ & $1.69(0.77-3.74)$ \\
\hline \multirow{2}{*}{$>=4$} & Prevalence \% & 41.4 & 42.0 & 37.4 \\
& OR(95\% CI) a & $2.42(1.26-4.65)$ & $0.94(0.27-3.37)$ & $1.93(0.90-4.13)$ \\
\hline
\end{tabular}

a - Adjusted for age, gender, education

\section{Keywords}

Adverse Childhood Experiences; Smoking; Nigeria; Youths

\section{Acknowledgments}

Community Medicine Department, UCH, Ibadan

Ibadan North Local Government, Oyo State

Oyo State Ministry of Health, Agodi, Ibadan, Oyo State

\section{References}

1. Anda RF, Butchart A, Felitti VJ, Brown DW. Building a framework for global surveillance of the public health implications of adverse childhood experiences. American Journal of Preventive Medicine. 2010;39(1):93-98.

2. Ramiro LS, Madrid BJ, Brown DW. Adverse childhood experiences (ACE) and health-risk behaviors among adults in a developing country setting. Child Abuse \& Neglect 2010;34:842-855.

3. CDC. Centers for Disease Control and Prevention, Department of Health and Human Services. Adverse childhood experiences study. 2005; http://www.cdc.gov/nccdphp/ACE/questionnaires.htm.

4. CDC. Centres for Disease Control and Prevention. National Youth Risk Behavior Survey. 2011; http://www.cdc.gov/healthyyouth/yrbs/ questionnaire_rationale.htm.

\author{
*Mobolaji M. Salawu \\ E-mail: sannibolaji@yahoo.com
}

